\title{
Highly Reproducible Techniques for Use in Systematic Bacteriology in the Genus Mycobacterium: Tests for Niacin and Catalase and for Resistance to Isoniazid, Thiophene 2-Carboxylic Acid Hydrazide, Hydroxylamine, and $p$-Nitrobenzoate
}

L. G. WAYNE, H. W. B. ENGEL, C. GRASSI, W. GROSS, J. HAWKINS, P. A. JENKINS, W. KÄPPLER, H. H. KLEEBERG, I. KRASNOW, E. E. NEL, S. R. PATTYN, P. A. RICHARDS, S. SHOWALTER, M. SLOSAREK, I. SZABO, I. TARNOK, M. TSUKAMURA, B. VERGMANN, AND E. WOLINSKY

Veterans Administration Hospital, Long Beach, California 90822; California College of Medicine, University of California, Irvine, California 92664; Rijks Instituut Voor de Volksgezonheid, Bilthoven, Holland; Universita di Pavia, Pavia, Italy; Veterans Administration Hospital, W. Haven, Connecticut 06516; University Hospital of Wales, Cardiff, U.K.; Tuberkulose-Forschungsinstitut, Berlin-Buch, German Democratic Republic; Tuberculosis Research Unit, Pretoria, South Africa; Instituut Voor Tropische Geneeskunde, Antwerpen, Belgium; Cleveland Metropolitan General Hospital, Cleveland, Ohio 44109; WHO International Reference Center for the Diagnosis of Tuberculosis, Prague, Czechoslovakia; "Koranyi" National Institute of Tuberculosis and Pulmonology, Budapest, Hungary; Forschunginstitut, Borstel, W. Germany; National Sanatorium, Chuba Chest Hospital, Obu Chita-Gun Aichi-Ken, Japan; and Statens Seruminstitut, Copenhagen, S. Denmark

This is a report of the second cooperative study, conducted by the International Working Group on Mycobacterial Taxonomy, to standardize and establish reproducibility of tests for classifying and identifying mycobacteria. Five tests that met specified rigorous criteria have already been described (Wayne et al., 1974). In the present report, six additional tests are described which meet these criteria. They are tests for production of niacin and of catalase and for resistance to $10 \mu \mathrm{g}$ of isonicotinic acid hydrazide (isoniazid) per $\mathrm{ml}, 1 \mu \mathrm{g}$ of thiophene 2carboxylic acid hydrazide per $\mathrm{ml}, 250 \mu \mathrm{g}$ of hydroxylamine hydrochloride per $\mathrm{ml}$, and $500 \mu \mathrm{g}$ of $p$-nitrobenzoate per $\mathrm{ml}$.

The International Working Group on Mycobacterial Taxonomy is an informal confederation of investigators who have undertaken a series of cooperative studies of the taxonomy of the genus Mycobacterium. The members also serve in an advisory capacity to the Subcommittee on Mycobacterium of the International Committee for Systematic Bacteriology. In the early "permissive" studies, the goal was to amass a large amount of data, derived from any tests the participants chose to apply to a selected population of mycobacteria, and to subject these data to numerical taxonomic analysis. From these studies it was possible to define a number of clusters, which generally corresponded to recognized species $(1,3,4,6,12)$. Furthermore, it was possible to identify the properties that were most consistently representative of the clusters. Subsequent cooperative studies were designed to establish the reproducibility of standardized techniques in order to identify the tests that appeared to be of the greatest utility for characterizing slowly growing mycobacteria. Criteria were estab- lished for reproducibility and discriminatory power of selected tests and, in the first cooperative study of techniques, five tests were described that met those criteria (14). In the second study, reported here, a special emphasis was placed on evaluation of tests that appeared to be most useful for discriminating among clusters within the "tuberculosis complex" of mycobacteria and between members of that complex and other nonpigmented, slowly growing mycobacteria. For purposes of this study, the tuberculosis complex was defined to include strains bearing the epithets Mycobacterium tuberculosis, $M$. bovis (including BCG), and $M$. africanum.

\section{MATERIALS AND METHODS}

Selection of tests for study. The general basis of test selection for the cooperative study was discussed previously (14). The tests selected for this second study yielded 15 characters, although some were redundant in that they compared susceptibility to drugs in two different culture media. A working manual, giving precise descriptions of all tests, was distributed to all participants. 
Cultures. The 14 strains listed in Table 2 were selected from the collection of $\mathrm{H}$. H. Kleeberg, who distributed freeze-dried preparations to all participants. These included American Type Culture Collection strains and others collected by Kleeberg from diverse sources. In contrast to the prior study (14) in which the investigators were asked to examine each strain voluntarily in triplicate, all strains in the present study were distributed in triplicate or quadruplicate with a different code number assigned to each replicate. Thus, a total of 44 cultures was analyzed, each coded separately. Little attempt was made to select strains most characteristic of their species.

Participation. In the prior study (14), the participants were free to choose the tests they wished to evaluate. As a result, too few laboratories examined some of the tests to permit an evaluation to be made. Therefore, all participants agreed to try to perform all of the tests included in this second study, on all of the cultures received. The tests were to be carried out exactly as described in the working manual. Data were submitted to the study coordinator (L. G. Wayne) for transcription and analysis.

The descriptions of techniques for six of the tests that were evaluated are presented below, since we believe that they yield highly reproducible data with taxonomic and determinative value.

Culture media. Only one type of culture medium, Lowenstein-Jensen (L-J), is required for all of the tests recommended here. Ogawa egg medium was substituted for L-J medium in one laboratory, with no apparent effect on results. This medium is prepared according to the formulation normally used by the laboratory. Drugs are added as indicated under specific tests.

For use in preparing inocula, in the niacin test, and in drug susceptibility tests, the medium is distributed to containers with screw caps, which may be loosened during incubation, or other closures that permit exchange of air, i.e., either tubes or flat bottles. The containers should receive between 4 and $10 \mathrm{ml}$ of medium and should be slanted so that the surface area is between 10 and $15 \mathrm{~cm}^{2}$.

For use in the semiquantitative catalase test, the L-J medium is prepared as indicated above, but it is dispensed in 5 -ml amounts to tubes ( 16 by $150 \mathrm{~mm}$ ) with screw caps or other closures that permit exchange of air. The medium is inspissated with the tube in an upright position; i.e., it is not slanted.

Final inspissation is at a temperature not to exceed $100^{\circ} \mathrm{C}$ and for no longer than $1 \mathrm{~h}$.

SCS. To simplify and standardize inocula for all of the tests included in these protocols, a standard cell suspension (SCS) is used throughout. It is prepared as follows.

Tubes or bottles of L-J medium are inoculated with a few drops of a barely turbid, aqueous suspension of the test organism. The L-J cultures are incubated at 35 to $37^{\circ} \mathrm{C}$ with loosened caps, in a wellhumidified incubator, for 21 to 28 days. The growth is scraped from the medium with caution to avoid carrying any of the medium along with the cells. The moist cells are weighed in a sterile tube. Sufficient sterile $0.067 \mathrm{M}$ phosphate buffer (pH 7.2), containing $0.05 \%$ Tween 80 , is added to yield a suspen- sion containing $10 \mathrm{mg}$ of cells per ml. A smooth suspension is made by agitating on a Vortex mixer (or by using, gently, a hand-operated tube homogenizer if a Vortex mixer is not available). If cells resist suspension, three sterile glass beads (about 5 $\mathrm{mm}$ diameter) are added and the suspension is agitated again. This type of suspension is the SCS to be used for all tests. It is sometimes used full strength and other times with further dilution. A fresh suspension is always prepared for a given run of tests.

Resistance to inhibitory agents. Hydroxylamine hydrochloride (HA), isoniazid (INH), p-nitrobenzoate (PNB), and thiophene 2-carboxylic acid hydrazide $(\mathrm{TCH})(2,8,9)$.

\section{Media and reagents}

a. Stock solutions of inhibitors: HA, $25 \mathrm{mg} / \mathrm{ml}$ in water; $\mathrm{INH}, 1 \mathrm{mg} / \mathrm{ml}$ in $50 \%$ ethanol; $\mathrm{PNB}, 50 \mathrm{mg} / \mathrm{ml}$ in propylene glycol; $\mathrm{TCH}, 1 \mathrm{mg} / \mathrm{ml}$ in $50 \%$ ethanol.

b. Media: L-J medium is distributed before inspissation in $100-\mathrm{ml}$ amounts. The indicated volumes of stock solutions of inhibitors are added, with shaking, to separate $100-\mathrm{ml}$ portions of L-J medium: HA, $1.0 \mathrm{ml}$ (final concentration in L-J medium, $250 \mu \mathrm{g}$ / $\mathrm{ml}$ ); INH, $1.0 \mathrm{ml}$ (final concentration, $10 \mu \mathrm{g} / \mathrm{ml}$ ); $\mathrm{PNB}, 1.0 \mathrm{ml}$ (final concentration, $500 \mu \mathrm{g} / \mathrm{ml}$ ); $\mathrm{TCH}$, $0.1 \mathrm{ml}$ (final concentration, $1 \mu \mathrm{g} / \mathrm{ml}$ ). A $200-\mathrm{ml}$ volume of drug-free medium is reserved for controls. It is especially important that the raw medium be shaken vigorously during the addition of PNB to minimize precipitation of this agent.

The medium is dispensed and inspissated as indicated above.

\section{Inoculum}

One drop (approximately $0.03 \mathrm{ml}$ ) of SCS is added to $3 \mathrm{ml}$ of sterile diluent as used for SCS. This barely turbid, diluted suspension is diluted further in the same diluent to $10^{-2}$ and $10^{-4}$. A $0.1-\mathrm{ml}$ volume of the $10^{-2}$ dilution is inoculated to all tubes of drug-containing media and to one drug-free control. A $0.1-\mathrm{ml}$ volume of the $10^{-4}$ dilution is inoculated only to another drug-free control.

\section{Time and conditions of incubation}

The cultures are incubated at 35 to $37^{\circ} \mathrm{C}$ for 21 days.

\section{Method of reading results}

After 21 days of incubation, the amount of growth on all media is recorded according to the following scale: no growth, $0 ; 1$ to 100 colonies, $1+$ (note actual number of colonies seen); innumerable colonies, $2+$; confluent growth, $3+$. (Note: According to the protocol for inoculum preparation, it should be possible to estimate number of colonies on the $10^{-4}$ inoculum control tube.)

\section{Reporting results}

The following report code for the observed results is used: growth on drug less than that seen on $10^{-4}$ 
control (i.e., less than $1 \%$ resistance), sensitive; growth on drug equal to or greater than that seen on the $10^{-4}$ control but less than that on the $10^{-2}$ control (1 to $10 \%$ resistance), partially resistant (inconclusive result); growth on drug equal to that seen on the $10^{-2}$ control ( $>10 \%$ resistance), resistant.

\section{Semiquantitative catalase (13)}

\section{Medium and reagents}

a. L-J medium as upright butts in tubes ( 16 by 150 $\mathrm{mm}$ ) as described previously.

b. Substrate stock solution: Hydrogen peroxide, 30\% (e.g., Superoxol). Keep refrigerated.

c. Foam base stock: A $10 \%$ solution of Tween 80 in water. Keep refrigerated.

\section{Inoculum}

One drop (approximately $0.03 \mathrm{ml}$ ) of SCS is diluted in $3 \mathrm{ml}$ of sterile distilled water. Three drops of this diluted suspension are inoculated to the surface of an L-J medium butt.

\section{Time and conditions of incubation}

The culture is incubated in a well-humidified incubator at 35 to $37^{\circ} \mathrm{C}$, with the caps on the tubes loosened, for 14 days.

\section{Method of reading results}

The 14-day-old L-J culture is examined to assure that growth has occurred. For each tube to be tested, $0.5 \mathrm{ml}$ of substrate stock is mixed with $0.5 \mathrm{ml}$ of foam base stock, and the mixture is allowed to reach room temperature. A 1-ml volume of the fresh mixture is added to the upright culture tube, at room temperature, in a bacteriological safety hood. A column of foam will form in the tube; the height of this column of foam (i.e., from the top of the liquid on the L-J medium to the top of the foam) is measured exactly 5 min after addition of the reaction mixture. If the foam nears the top of the tube before $5 \mathrm{~min}$ has elapsed, the tube may be discarded into a pan of disinfectant, and the response should be recorded as "over $60 \mathrm{~mm}$ " of foam.

\section{Special problems or pitfalls}

In some cases, catalase production depends on adequate aeration, so the looseness of the caps should be checked. Agar medium may not be substituted for L-J medium since it gives very erratic results. Be sure that the $\mathrm{H}_{2} \mathrm{O}_{2}$ used is $30 \%$ and not the $3 \%$ variety commonly available in pharmacies.

\section{Reporting results}

Although the actual height of the foam column is recorded, the results may be reported in the following manner: less than $31 \mathrm{~mm}$ of foam, low or no catalase activity; between 31 and $45 \mathrm{~mm}$, inconclusive result; more than $45 \mathrm{~mm}$, high catalase activity.

\section{Niacin accumulation (5)}

\section{Media and reagents}

a. L-J medium.

b. Aniline solution: A 4-ml volume of fresh, clear, colorless aniline (redistill if necessary) is mixed with $96 \mathrm{ml}$ of $95 \%$ ethanol. Store in refrigerator.

c. Cyanogen bromide solution: A 10-g amount of $\mathrm{BrCN}$ is dissolved in $90 \mathrm{ml}$ of water. Alternatively, one may add water to a bottle of $\mathrm{BrCN}$ crystals in such an amount that there are always crystals left in the bottom, i.e., a saturated solution. Water may be added to replenish the solution as long as crystals remain. Store tightly capped in refrigerator. CAUTION: Severe lacrimator.

\section{Inoculum}

One drop (approximately $0.03 \mathrm{ml}$ ) of SCS is diluted in $3 \mathrm{ml}$ of sterile distilled water. Three drops of this diluted suspension are inoculated into each of two L-J tubes.

\section{Time and conditions of incubation}

The cultures are incubated at 36 to $37^{\circ} \mathrm{C}$, loosely capped, in a very well-humidified incubator. One culture is removed for testing after 3 weeks of incubation, and the other is removed after 6 weeks of incubation. If a positive reaction is obtained after 3 weeks, it is not necessary to continue testing.

\section{Method of reading results}

The culture is flooded with $0.5 \mathrm{ml}$ of sterile water. (If growth is confluent, cut through the surface into the medium with a sterile applicator stick or Pasteur pipette to be sure that water contacts the medium.) The slant is laid flat for $60 \mathrm{~min}$ and then raised to an upright position for $5 \mathrm{~min}$ to permit water to drain to the bottom. The aqueous extract is removed to a screw-capped test tube (13 by $100 \mathrm{~mm}$ ). Add, in sequence, $0.5 \mathrm{ml}$ of the aniline-ethanol solution and then $0.5 \mathrm{ml}$ of the cyanogen bromide solution. The tube is capped and examined for development of a definite yellow color within $5 \mathrm{~min}$. A convenient color standard may be prepared by dispensing $1.5 \mathrm{ml}$ of an aqueous solution of picric acid $(10 \mu \mathrm{g} / \mathrm{ml})$ into a similar tube and sealing tightly with paraffin. The yellow color for a positive niacin reaction should be as dark or darker than this standard. The standard, if properly sealed, should keep indefinitely.

\section{Special problems or pitfalls}

The cyanogen bromide is a severe lacrimator. Always use a well-ventilated hood and pipette only with a rubber bulb. Tubes to be discarded may be immersed in a standard phenolic disinfectant containing $1 \%$ sodium carbonate to neutralize the reagent. The L-J medium rarely may contribute some color to the test. When in doubt about interpretation, repeat the test. 


\section{Reporting results}

Positive reactions are reported according to the week when they first appeared (i.e., 3 or 6 ).

\section{RESULTS}

Exclusion of data. In one laboratory, the niacin test was read only at 9 weeks so the data could not be used. Two laboratories failed to get a positive niacin reaction with any of the cultures, and it was judged that defective reagents may have been used; data from these two laboratories were also excluded from analysis. One laboratory failed to submit data on the niacin and catalase tests and $\mathrm{TCH}$ resistance, without explanation. In two laboratories, all strains appeared to be completely susceptible to $10 \mu \mathrm{g}$ of INH per $\mathrm{ml}$, and in one laboratory all were completely resistant to $500 \mu \mathrm{g}$ of PNB per ml, suggesting that errors in weighing the inhibitory agents had occurred; these data were also excluded from analysis. One other laboratory was unable to obtain the PNB for the test. For every test described, data from at least 10 laboratories were included in the final analysis. In no case was any strain subjected to fewer than 17 replications of any test, and in most cases the number of replications per strain exceeded 25 .

Assignment of characters. As discussed previously $(10,11)$, the selection of criteria for defining a Mycobacterium species as "positive" or "negative" in a given test is often based on distribution frequencies of quantitative test scores; i.e., the definition of characters for distinguishing strains in this genus frequently depends on quantitative differences in test response rather than on absolute, all-or-none responses. The chance of an error of interpretation is greatest in the immediate proximity of the quantitative cutoff point. After some preliminary analysis of data, a decision was made to treat certain ranges of scores in five of the six tests reported here as "inconclusive." That is, regardless of whether scores in the selected range were treated as "positive" or as "negative," a high number of errors would have been introduced, so these results were rejected. Thus, the reporting strategy in routine practice would be to record scores in the intermediate ranges as inconclusive and indicate that the test should be repeated. Since all of the tests in this study were performed on triplicate coded cultures in each laboratory, this strategy was tested by examining the results of all three replications in each triad that contained at least one "inconclusive" report. A combined total of 112 such triads, observed in the tests for resistance to TCH, INH, HA, and PNB and for catalase activity, was analyzed. (The numbers of inconclusive entries are indicated for each of these tests in Table 1.) Twenty-six percent of the additional replications within these 112 triads for the five tests were also in the "inconclusive" category; $65 \%$ were in the "correct" category, i.e., in agreement with the majority of replications from all combined laboratories; and 9\% were in the "conclusive" range but in disagreement with the majority. For no strain did the rejected (inconclusive) range of values correspond to the score reported by the majority of participants for any of these five tests. Furthermore, for none of the tests described did the "inconclusive" results correspond to more than $10.2 \%$ of the total number of reports. The ranges of "inconclusive" values are indicated under the descriptions of the tests in Materials and Methods. No scores were treated as inconclusive in the niacin tests.

Analysis of results. The transcription and analysis of data followed the same principles as were applied to the prior study (14). The only change was the exclusion of inconclusive results from the calculations of percent agreement and variance.

The test result obtained by a majority of participants for each strain was considered the "concensus" result for that strain and is the basis for the data presented in Table 1. The total number of results in agreement with strain concensus obtained for a test was expressed as a percentage of the total number of responses submitted for the test, and the result is designated as mean percent agreement. The variance $\left(S_{1}{ }^{2}\right)$ was calculated from formula 14 of Sneath and Johnson (7). The value for degrees of freedom $(N-1)$ in that formula were based on average values of $N$ per strain for each test since not all strains were subjected to exactly the same number of replications for a given test.

The number of laboratories showing over $90 \%$ agreement with concensus results was also tabulated, as was the number of strains yielding over $90 \%$ positive and over $90 \%$ negative results in pooled data for a given test.

This study was designed with the intention that each laboratory would perform each test on three or, in two cases, four coded replicates of each of the 14 strains studied. In some instances, only one or two replications were available, and these were not included in the analysis of internal consistency of laboratories. For this analysis, the number of strains on which triplicate or quadruplicate results were available for a given test was added up for all laboratories, and the sum of sets was designated $T$. 
The number of sets for which all replicate answers were in agreement with each other was designated $C$. The mean percent internal consistency is thus $(C / T) \times 100$. This is not a measure of "correctness" of answer but only of reproducibility within laboratories. As has been discussed before (14), the values of mean percent agreement with strain concensus are not strictly comparable to the scores for internal consistency within laboratories, since, in determining internal consistency of laboratories, a single disagreement among three or four replications was recorded as a replication failure for that entire set.

As before, we present detailed descriptions and results only for the techniques that met all four of the following rigorous criteria. (i) Ten or more replicate data (combined from all laboratories) were received for each test strain subjected to the test. (ii) The mean percent agreement for that test was equal to or exceeded $90 \%$. (iii) At least one strain was recorded as positive in at least $90 \%$ of 10 or more replications of the test. (iv) At least one additional strain was recorded as negative in at least $90 \%$ of 10 or more replications of the test.

Nine of the procedures examined met these criteria, but four of these dealt with resistance to TCH. The one with the greatest reproducibility and differential power employed TCH at a concentration of $1 \mu \mathrm{g} / \mathrm{ml}$ in L-J egg-based medium. The test employing $1 \mu \mathrm{g}$ of TCH per ml in Middlebrook-Cohn 7H10 agar also had a very high reproducibility score $(96.9 \%$ agreement with concensus); however, inasmuch as the other tests to be recommended for determina- tion of resistance to inhibitory agents employ the L-J egg medium, it was decided to restrict our present recommendations to the use of this medium. High scores were also recorded for resistance to $10 \mu \mathrm{g}$ of TCH per $\mathrm{ml}$ in both L-J medium (94.3\%) and 7H10 medium (91.5\%), but the additional disagreements seen with this higher concentration were largely contributed by observations of inhibition of $M$. tuberculosis in some replications. Since the major value of the $\mathrm{TCH}$ resistance test is to distinguish between $M$. tuberculosis and $M$. bovis, the use of the lower concentration is recommended.

The analyses of results for the six recommended tests are presented in Tables 1 and 2.

There were four tests that appeared to have good resolving power in the prior permissive studies $(4,12)$, but they are neither described here nor included in the tables of results because they failed to meet the criteria for reproducibility. These were tests for growth at $25^{\circ} \mathrm{C}$, for production of nicotinamidase and pyrazinamidase, and for ability to reduce nitrate.

In the test for growth at $25^{\circ} \mathrm{C}$, using a $1: 100$ dilution SCS on L-J slants, there was a clear bimodal distribution of reproducibility scores. Nine laboratories performed in the range of 90 to $100 \%$, with a mean of $93.8 \%$; one had $87.1 \%$ agreement; and the remaining five performed in the range of 71 to $80 \%$, with a mean of $76.6 \%$. Among the five laboratories with scores below $90 \%$, the data suggested that in three of them the incubators used were probably operating at a temperature higher than $25^{\circ} \mathrm{C}$, since $95 \%$ of the errors were in the direction of false-positive results. Similarly, the incubators of the other

TABLE 1. Reproducibility and differential consistency of six tests.

\begin{tabular}{|c|c|c|c|c|c|c|c|c|c|c|c|}
\hline \multirow{3}{*}{ Property } & \multicolumn{5}{|c|}{ Entry } & \multicolumn{3}{|c|}{ Laboratory } & \multicolumn{3}{|c|}{ No. of strains } \\
\hline & \multirow{2}{*}{$\begin{array}{l}\text { Total } \\
\text { no. }\end{array}$} & \multirow{2}{*}{$\begin{array}{l}\text { \% Incon- } \\
\text { clusive }\end{array}$} & \multirow{2}{*}{$\begin{array}{l}\text { No. con- } \\
\text { clusive }\end{array}$} & \multirow{2}{*}{$\begin{array}{c}\text { Mean } \% \\
\text { agree- } \\
\text { ment }\end{array}$} & \multirow{2}{*}{$\begin{array}{l}\text { Vari- } \\
\text { ance }\end{array}$} & \multirow[b]{2}{*}{ Total } & \multirow{2}{*}{$\begin{array}{c}\text { No. } 90 \% \\
\text { agree- } \\
\text { ment }\end{array}$} & \multirow{2}{*}{$\begin{array}{c}\text { Mean \% } \\
\text { internal } \\
\text { consis- } \\
\text { tency }\end{array}$} & \multirow[b]{2}{*}{ Total } & \multicolumn{2}{|c|}{$\geq 90 \%$} \\
\hline & & & & & & & & & & Positive & Negative \\
\hline Resistance $^{a}$ to: & & & & & & & & & & & \\
\hline $\mathrm{HA}, 250 \mu \mathrm{g} / \mathrm{ml}$ & 452 & 10.2 & 406 & 95.8 & 0.039 & 14 & 14 & 90 & 14 & 8 & 4 \\
\hline INH, $10 \mu \mathrm{g} / \mathrm{ml}$ & 382 & 6.8 & 356 & 92.7 & 0.067 & 12 & 9 & 91 & 14 & 3 & 6 \\
\hline $\mathrm{PNB}, 500 \mu \mathrm{g} / \mathrm{ml}$ & 386 & 13.2 & 335 & 91.3 & 0.068 & 12 & 8 & 91 & 14 & 3 & 6 \\
\hline $\mathrm{TCH}, 1 \mu \mathrm{g} / \mathrm{ml}$ & 436 & 6.7 & 407 & 97.3 & 0.024 & 13 & 12 & 96 & 14 & 11 & 2 \\
\hline $\begin{array}{l}\text { Catalase, semi- } \\
\text { quantitative }\end{array}$ & 475 & 5.5 & 449 & 94.7 & 0.048 & 13 & 10 & 95 & 14 & 4 & 7 \\
\hline Niacin $^{c}$ & 346 & & 346 & 93.4 & 0.057 & 10 & 8 & 85 & 14 & 2 & 8 \\
\hline
\end{tabular}

a The term "positive" in the resistance tests denotes growth of more than $10 \%$ of the inoculum population, and "negative" denotes growth of fewer than $1 \%$.

"In the catalase test, "positive" denotes production of more than $45 \mathrm{~mm}$ of foam, and "negative" means less than $30 \mathrm{~mm}$.

${ }^{c}$ In the niacin test, cultures that give a color reaction after 3 or 6 weeks are treated as positive. 
TABLE 2. Frequency of test responses by strain

\begin{tabular}{|c|c|c|c|c|c|c|c|c|c|c|c|c|c|}
\hline \multirow{3}{*}{ Mycobacterium strain } & \multirow{3}{*}{$\begin{array}{c}\text { Replicate } \\
\text { culture code } \\
\text { no. }\end{array}$} & \multirow{3}{*}{$\begin{array}{c}\text { Kleeberg } \\
\text { stock culture } \\
\text { no. }\end{array}$} & \multicolumn{6}{|c|}{$\begin{array}{c}\text { Conclusive results that were posi- } \\
\text { tive }(\%)\end{array}$} & \multicolumn{5}{|c|}{$\begin{array}{c}\text { Total results that were con- } \\
\text { clusive }(\%)\end{array}$} \\
\hline & & & \multicolumn{4}{|c|}{ Resistance to ${ }^{a}$ : } & \multirow{2}{*}{ 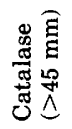 } & \multirow[b]{2}{*}{ 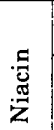 } & \multicolumn{4}{|c|}{ Resistance to: } & \multirow{2}{*}{ 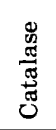 } \\
\hline & & & 至 & 要 & $\sum_{Z}^{n}$ & 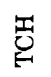 & & & $\overleftrightarrow{4}$ & 昰 & $\frac{m}{a}$ & 焉 & \\
\hline 1. M. tuberculosis & $4,22,43$ & $332 / 73$ & 13 & 0 & 6 & 100 & 0 & 88 & 100 & 100 & 100 & 95 & 100 \\
\hline 2. M. $t$ & 1,1 & TC 77 & 3 & 13 & 0 & 9 & 5 & 93 & 95 & 89 & 94 & 84 & 100 \\
\hline 3. M. tuber & $8,18,48,50$ & TC & 5 & 7 & 0 & 77 & 3 & 100 & 100 & 97 & 97 & 83 & 100 \\
\hline 4. M. africanum & $49,51,52$ & RIST: R5283 & 4 & 4 & 0 & 4 & 12 & 15 & 96 & 100 & 100 & 100 & 100 \\
\hline 5. M. bovi & 34 , & OP 38 & 18 & 87 & 9 & 96 & 3 & 4 & 96 & 96 & 96 & 93 & 97 \\
\hline 6. M. bovis & $3,14,36$ & TC 14 & 0 & 0 & 0 & 0 & 0 & 29 & 96 & 100 & 100 & 93 & 100 \\
\hline 7. $M$. & $17,30,46$ & ATCC 25275 & 95 & 25 & 94 & 100 & 95 & 74 & 79 & 76 & 82 & 83 & 83 \\
\hline 8. M. gastri & $15,23,32$ & ATCC 25158 & 77 & 6 & 12 & 95 & 0 & 0 & 62 & 100 & 90 & 91 & 96 \\
\hline 9. M. kansasii subsp. album & $21,27,29,53$ & ATCC 25223 & 100 & 6 & 74 & 100 & 100 & 0 & 73 & 97 & 73 & 98 & 100 \\
\hline 10. M. $n$ & 13 , & ATCC 19530 & 97 & 100 & 19 & 100 & 97 & 0 & 100 & 100 & 93 & 100 & 100 \\
\hline 11. M. ter & $6,12,26$ & ATCC 15755 & 100 & 100 & 100 & 100 & 88 & 0 & 95 & 97 & 100 & 97 & 79 \\
\hline 12. M. triviale & $5,20,40$ & ATCC 23292 & 100 & 100 & 100 & 100 & 91 & 8 & 94 & 100 & 70 & 97 & 94 \\
\hline 13. M. $i$ & 10,2 & ATCC 13950 & 100 & 13 & 67 & 100 & 23 & 0 & 87 & 94 & 79 & 95 & 77 \\
\hline 14. M. avium & $7,16,33$ & ATCC 19421 & 100 & 75 & 89 & 100 & 0 & 0 & 81 & 65 & 58 & 97 & 100 \\
\hline
\end{tabular}

${ }^{a}$ In L-J medium.

three laboratories appeared to have been set too low, with $81 \%$ of their errors in the direction of false-negative results. If one considers only the data from laboratories with greater than $90 \%$ reproducibility in this test, then all six strains of $M$. tuberculosis, $M$. africanum, and $M$. bovis exhibited no growth at $25^{\circ} \mathrm{C}$ in 94 to $100 \%$ of the replications. $M$. gastri, $M$. simiae, and $M$. avium yielded less than $90 \%$ reproducibility, even in these laboratories. All of the other strains grew at $25^{\circ} \mathrm{C}$, with reproducibility ranging from 95 to $100 \%$.

In the other three tests mentioned above, the laboratories performed over a very broad range of reproducibilities; the mean agreement with concensus was less than $90 \%$ for each. The distributions of false-positive and false-negative reports was in approximate proportion to what would be expected from the distribution of concensus results of the strains employed, so no clear inferences could be derived as to the reasons for poor reproducibility. Further studies are in process to try to identify the factors involved.

\section{DISCUSSION}

To date, the two cooperative studies on reproducibility of techniques provide 11 characters with great differential power for classifying and identifying mycobacteria. The various types of errors and their implications were discussed in our previous report (14). The improvement in reliability obtained by definition of "inconclu- sive" ranges of results is noted in the Results section of the present report.

Four of the six tests described in this report are based on resistance to growth inhibitors. The HA test and the PNB test were evaluated only in L-J egg medium. However, tests for resistance to INH $(10 \mu \mathrm{g} / \mathrm{ml})$ and to TCH (1 and $10 \mu \mathrm{g} / \mathrm{ml}$ ) were performed in both L-J egg medium and in $7 \mathrm{H} 10$ agar. In almost every case, the results on egg medium were more reproducible than those on agar. For $1 \mu \mathrm{g}$ of TCH per $\mathrm{ml}$, the two media were comparable, with variances of 0.024 and 0.025 , respectively. The superiority of egg medium over agar was more pronounced in the other resistance tests. For $10 \mu \mathrm{g}$ of TCH per $\mathrm{ml}$, the variances were 0.049 and 0.077 for L-J and agar media, respectively, and for $10 \mu \mathrm{g}$ of INH per ml they were 0.067 and 0.102 , respectively. Only the $10 \mu \mathrm{g}$ of INH per $\mathrm{ml}$ in $7 \mathrm{H} 10$ failed to meet the criteria for reproducibility. It must be pointed out that inferences should not be drawn on the relative suitability of these two media for drug susceptibility testing for therapeutic purposes; the drug levels and the strains reported here were selected to evaluate these tests for taxonomic, not therapeutic, purposes.

On the basis of the very small selection of strains represented, caution must be exercised in making taxonomic interpretations on the basis of this study alone. Nevertheless, it is striking that the test for resistance to HA provided a fairly sharp division between members 
of the tuberculosis complex and other nonpigmented, slowly growing mycobacteria. The poorest reproducibility was seen with $M$. gastri, suggesting that the variability of this species noted by Meissner et al. (4) in this test may reflect poor reproducibility at this concentration rather than a strain-to-strain difference. The same may hold true for $M$. xenopi, which also showed variability in the study of Meissner et al. but which was not represented in the present study.

The sole reason for inclusion of a test for resistance to a low concentration of $\mathrm{TCH}$ is the fact that $M$. bovis is sensitive to the drug (2). Of the two strains examined, one, $\mathrm{BCG}$, yielded $96 \%$ conclusive results and no instance of resistance. The other strain of $M$. bovis was an INHresistant mutant, and it is known that such mutants are also resistant to TCH (2). The strain of $M$. africanum included in this study behaved like a wild $M$. bovis strain in this regard, and reproducibility was very high.

It had been recommended previously that a cutoff value of $45 \mathrm{~mm}$ of foam be used for defining high and low catalase reactions (11). When this criterion was applied to the data derived in the present study, the agreement with concensus was $91.8 \%$. Of a total of 26 entries that fell in the range of 31 to $45 \mathrm{~mm}$ (i.e., $5.5 \%$ of total entries), 15 were in disagreement with the concensus based on a 45 -mm cutoff; these 15 represented $38.5 \%$ of all of the disagreements for the test. This led to the decision to treat scores in this range as inconclusive. This, in turn, raised the score to $94.7 \%$ agreement with concensus for the remaining $94.5 \%$ of the reports. Therefore, it is recommended that any culture that yields between 31 and $45 \mathrm{~mm}$ of foam in this test be retested. The inconclusive results appeared in 15 replicate triads. The 30 additional replications within these triads yielded: $30 \%$ inconclusive results; $53 \%$ conclusive results, in agreement with concensus; and 17\% conclusive results, which disagreed with concensus.

In terms of practical importance, the niacin test is the most significant determinative tool for mycobacteria. Its importance lies in the fact that $M$. tuberculosis yields a positive reaction, which distinguishes it from almost all other mycobacteria. As in all tests, error is undesirable, but if some error is to occur it is probably better to err in the direction of a false-negative result with this test. The greatest volume of determinative work done with mycobacteria involves the identification of $M$. tuberculosis. In routine clinical laboratory practice, great weight is placed on the niacin test. If a falsepositive result is recorded, there is a danger that the culture would be assumed to be $M$. tuberculosis and no further studies would be performed; the error would remain undetected. If a false-negative result is recorded, further tests are done to establish an identification and, in the course of the studies, the error would be detected. It must be noted, however, that $M$. simiae, although more variable than M. tuberculosis, does give a positive niacin reaction. Furthermore, $M$. bovis $\mathrm{BCG}$ also gave a significant number of positive reactions in this study.

The optimal schedule for the niacin test would be to set up duplicate cultures and test one strain after 3 weeks of incubation. (At this time, 58 of 70 reports on the $M$. tuberculosis cultures in this study were positive.) If the result is positive, the test is considered as completed; if it is negative, the duplicate culture is reincubated for an additional 3 weeks and then tested. Any incubation beyond this period is contraindicated since false-positive results will increase in numbers (when the test was read at 9 weeks, there was only $89.2 \%$ agreement with concensus). It is clear, furthermore, that the niacin test alone is not sufficient to assure identification of $M$. tuberculosis, even in the absence of pigment. The HA resistance test appears to be a very useful adjunct to this test to identify members of the tuberculosis complex. Furthermore, the observation of a $29 \%$ incidence of positive niacin reactions with BCG makes it evident that the test for resistance to 1 $\mu \mathrm{g}$ of TCH per ml should be performed routinely also.

In both of the cooperative studies on reproducibility completed to date, attempts were made to evaluate the tests for growth at various temperatures. In neither study did such tests meet our criteria for inclusion in the published reports. Nevertheless, tests for the ability of an organism to grow at 25 and $45^{\circ} \mathrm{C}$ appear to provide useful information (4). As indicated in Results, the poor reproducibility observed in some laboratories appeared to reflect inadequate control of temperatures. Individual laboratories may choose to determine these characters, but it is essential that adequate temperature-monitoring equipment be available and that such equipment be calibrated against a standard thermometer that meets the specifications of an appropriate testing agency, such as the National Bureau of Standards. Temperatures should be held to $\pm 0.25^{\circ} \mathrm{C}$ variation ( $\mathrm{J}$. Marks, personal communication).

\section{ACKNOWLEDGMENT}

This work was supported by Veterans Administration project $1695-01$. 


\section{REPRINT REQUESTS}

Address reprint requests to: Dr. L. G. Wayne, Veterans Administration Hospital, 5901 East 7th St., Long Beach, Calif. 90801.

\section{LITERATURE CITED}

1. Goodfellow, M., A. Lind, H. Mordarska, S. Pattyn, and M. Tsukamura. 1974. A co-operative numerical analysis of cultures considered to belong to the rhodochrous taxon. J. Gen. Microbiol. 85:291-302.

2. Juhlin, I. 1960. Methods for the grouping and typing of mycobacteria. 2. Differentiation of Mycobacterium tuberculosis into typus humanus and typus bovinus. Acta Pathol. Microbiol. Scand, 50:188-194.

3. Kubica, G. P., I. Baess, R. E. Gordon, P. A. Jenkins, J. B. G. Kwapinski, C. McDurmont, S. R. Pattyn, H. Saito, V. Silcox, J. L. Stanford, K. Takeya, and $M$. Tsukamura. 1972. A cooperative numerical analysis of rapidly growing mycobacteria. J. Gen Microbiol. 73:55-70.

4. Meissner, G., K. H. Schröder, G. E. Amadio, W. Anz, S. Chaparas, H. W. B. Engel, P. A. Jenkins, W. Káppler, H. H. Kleeberg, E. Kubala, M. Kubin, D. Lauterbach, A. Lind, M. Magnusson, Zd. Mikova, S. R. Pattyn, W. B. Schaeffer, J. L. Stanford, M. Tsukamura, L. G. Wayne, I. Willers, and E. Wolinsky. 1974. A cooperative numerical analysis of nonscotoand nonphotochromogenic slowly growing mycobacteria. J. Gen. Microbiol. 83:207-235.

5. Runyon, E. H., M. J. Selin, and H. W. Harris. 1959 Distinguishing mycobacteria by the niacin test. Am. Rev. Tuberc. Pulm. Dis. 79:663-665.

6. Saito, H., K. Yamaoka, and K. Kiyotani. In vitro properties of Mycobacterium lepraemurium strain Keishicho. Submitted for publication.
7. Sneath, P. H. A., and R. Johnson. 1972. The influence on numerical taxonomic similarities of errors in $\mathrm{mi}$ crobiological tests. J. Gen. Microbiol. 72:377-392.

8. Tsukamura, M. 1965 . Differentiation of mycobacteria by susceptibility to hydroxylamine and 8-azaguanine. J. Bacteriol. 90:556-557.

9. Tsukamura, M., and S. Tsukamura. 1965. Differentiation of Mycobacterium tuberculosis and Mycobacterium bovis by p-nitrobenzoic acid susceptibility. Tubercle 45:64-65.

10. Wayne, L. G. 1964 . The mycobacterial mystique: deterrent to taxonomy. Am. Rev. Respir. Dis. 90:255-257.

11. Wayne, L. G. 1967. Selection of characters for an Adansonian analysis of mycobacterial taxonomy. J. Bacteriol. 93:1382-1391.

12. Wayne, L. G., T. M. Dietz, C. Gernez-Rieux, P. A. Jenkins, W. Käppler, G. P. Kubica, J. B. G. Kwapinski, G. Meissner, S. R. Pattyn, E. H. Runyon, K. H. Schröder, V. A. Silcox, A. Tacquet, M. Tsukamura, and E. Wolinsky. 1971. A co-operative numerical analysis of scotochromogenic slowly growing mycobacteria. J. Gen Microbiol, 66:255-271.

13. Wayne, L. G., and J. R. Doubek. 1968. Diagnostic key to mycobacteria encountered in clinical laboratories. Appl. Microbiol. 16:925-931.

14. Wayne, L. G., H. C. Engbaek, H. W. B. Engel, S. Froman, W. Gross, J. Hawkins, W. Käppler, A. G. Karlson, H. H. Kleeberg, I. Krasnow, G. P. Kubica, C. MeDurmont, E. E. Nel, S. R. Pattyn, K. H. Schröder, S. Showalter, I. Tarnok, M. Tsukamura, B. Vergman, and E. Wolinsky, 1974. Highly reproducible techniques for use in systematic bacteriology in the genus Mycobacterium: tests for pigment, urease, resistance to sodium chloride, hydrolysis of Tween 80 and $\beta$-galactosidase. Int. J. Syst. Bacteriol. 24:412-419. 